\title{
Transcatheter embolization of abdominal aortic endograft endoleaks using onyx and coils: mid-term imaging follow-up
}

This article was published in the following Dove Press journal:

Journal of Vascular Diagnostics and Interventions

3 March 2017

Number of times this article has been viewed

\section{Christopher A Ford \\ Benjamin B Lange \\ Christopher S Morris}

Department of Radiology, University of Vermont Health Network, University of Vermont Medical Center, Burlington, VT, USA
Correspondence: Christopher S Morris Department of Radiology, University of Vermont Health Network, University of Vermont Medical Center, I I I Colchester Avenue

Burlington, VT 05402, USA

Tel +l 8028475684

Email christopher.morris@uvmhealth.org
Purpose: To evaluate the efficacy and safety of ethylene vinyl alcohol copolymer (Onyx) with or without coils in treatment of type II endoleaks associated with abdominal aortic endografts.

Materials and methods: The medical records of 14 patients (12 men and 2 women, mean age 73 years) with type II endoleaks associated with abdominal aortic endografts, and treated with Onyx, with or without coils, were reviewed. These patients underwent 19 type II endoleak embolization procedures. Time to follow up computed tomography angiogram (CTA), initial and follow-up aneurysm sac characteristics, embolization access technique, use of coils, volume and type of Onyx used, and complications were recorded.

Results: Mean procedure time was 124 minutes (range, 51-237 minutes), and mean volume of Onyx used per procedure was $2.1 \mathrm{cc}$ (range, 1.5-3). Mean follow-up time between initial and final CTA was 19.9 months (range, 0.5-64.4). After one or more treatments, follow-up imaging documented complete occlusion of the endoleaks in 10 of 14 patients. Mean sac size decreased by an average of $0.3 \mathrm{~cm}$ in those with successful embolization and increased by an average of 0.4 $\mathrm{cm}$ in those with failed embolization. One major complication (infection, 5.2\%) occurred before adding prophylactic antibiotics to our protocol. No significant inadvertent embolization occurred. Conclusion: This study contributes to the growing body of data regarding safety and efficacy of treating type II endoleaks using Onyx. Potential benefits are both technical and economic. As we found advantages with the use of Onyx, additional studies are warranted.

Keywords: endoleak, onyx, embolization

\section{Introduction}

After aortic endograft placement, flow in and out of the aneurysm sac through patent branch arteries is the most common type of endoleak. These "type II endoleaks" are estimated to arise in approximately $9 \%-30 \%$ of patients after endovascular aneurysm repair (EVAR). ${ }^{1}$ Reported spontaneous resolution of type II endoleaks ranges from $33 \%$ to $50 \%$ within the first year. ${ }^{1,2}$ Those that do not resolve within the first year are unlikely to do so spontaneously and are referred to as "persistent" type II endoleaks. ${ }^{1}$

Treatment of type II endoleaks is generally performed via transcatheter therapeutic embolization. ${ }^{3}$ Numerous techniques and materials for embolization of endoleaks have been described. Access to the aneurysm sac is typically achieved with either a transarterial approach or direct needle puncture under imaging guidance. ${ }^{1}$ Many materials have been used for endoleak embolization including coils, gelatin sponge, thrombin, and tissue adhesive (cyanoacrylate), among others. ${ }^{4}$ One product being used at some centers is ethylene vinyl alcohol copolymer (Onyx; Covidien, Dublin, Republic of Ireland). Onyx is a nonadherent, cohesive, liquid copolymer embolic 
agent that is permanent and radiopaque due to micronized tantalum powder within the product. In the United States, the Food and Drug Administration has approved Onyx for use in embolization of intracranial aneurysms not amenable to surgical clipping and for presurgical embolization of arteriovenous malformations. This manuscript describes our tertiary care center's experience with off-label use of Onyx, with or without coils, for embolization of endoleaks.

\section{Materials and methods}

This study was performed as a retrospective analysis of patients at our tertiary care referral center. A University of Vermont Institutional Review Board, Committee on Human Research in the Medical Sciences, exemption was obtained prior to acquisition of patient data. As this was a retrospective study, written informed consent from each patient was not required by the Institutional Review Board. The departmental database was searched for patients who had undergone embolization treatment of an abdominal aortic aneurysm sac endoleak with Onyx, between January 2007 and November 2012. Two inclusion criteria required satisfaction for inclusion to the study. The first criterion was referral for treatment from a vascular surgeon based on computed tomography angiography (CTA) diagnosis of either suspected type II endoleak persisting greater than 6 months, or suspected type II endoleak associated with a significant increase in aneurysm sac diameter. Throughout the review period of this manuscript, the threshold for treating based on sac growth evolved from greater than $2 \mathrm{~mm}$ to greater than $5 \mathrm{~mm}$. The second criterion was the use of Onyx 34 for endoleak embolization, with or without the use of adjunctive coils.

A total of 14 patients were identified meeting our inclusion criteria. These patients underwent a total of 19 procedures. Information was gathered using electronic medical records and the picture archiving and communication system. Review of the initial aneurysm characteristics (including diameter) and the initial aneurysm repair procedure was performed. The period of time between initial EVAR and follow-up demonstration of persistent endoleak, or aneurysm sac dilation, was noted.

Embolization access techniques were selected on a case by case basis by the attending interventional radiologist and included six transarterial approaches, eight computed tomography (CT)-guided direct punctures, and five fluoroscopicguided direct punctures. Once access was obtained, the decision to use adjunctive 0.018 Hilal (Cook, Bloomington, IN, USA) pushable coils was made by the attending interventional radiologist. All cases initially accessed by CT-guided direct puncture had a coil placed in the CT scanner room.
This was done to have a fluoroscopic puncture target should inadvertent loss of access occur in transport. Four additional cases had one or more coils deployed to occupy space if the suspected required volume of Onyx would be greater than two doses $(3 \mathrm{~mL})$. In all cases, an attempt was made to fill the entire endoleak flow channel within the aneurysm sac with Onyx, with or without embolization coils. Onyx 34, which is the least penetrable form, was used.

Follow-up evaluation for aneurysm sac size and persistent or new endoleak was performed with CTA in all except one postprocedure follow-up episode (which used duplex ultrasound). The outcomes reported include endoleak type, initial and final aneurysm sac diameter for each procedure, presence of endoleak after each procedure, use of coils, and volume of Onyx 34 used. Change in aneurysm sac diameter for clinically successful embolization attempts was compared to change in sac diameter for failed attempts using a twosample $t$-test analysis.

\section{Results}

Application of our inclusion criteria from January 2007 to November 2012 identified 14 patients, including 12 men and two women. Patient ages ranged from 56 to 83 years of age, with a mean age of 73 years. A total of 19 technically successful endoleak embolization procedures were performed. Ten patients were treated with a single procedure, three patients with two procedures, and one patient underwent three endoleak embolization procedures. Twelve procedures included use of both Onyx and coils. Seven procedures were performed with Onyx alone (Table 1).

The mean interval from time from index endograft placement to first endoleak treatment was 13.3 months (range of 1-60 months). This excludes one patient in whom the endograft placement date was unknown. The mean embolization procedure time was 124 minutes (range of 51-237 minutes). In addition to time in the angiography suite, procedure time included time in the CT scanner as well as transportation time between the CT scanner and the angiography suite when applicable. The time from embolization procedure to postprocedural follow-up with CTA and duplex ultrasound ranged from 0.5 to 64.4 months, with a mean of 19.9 months and a median of 13.2 months.

An additional technical outcome was the volume of Onyx used. A single dose of Onyx 34 (1.5 mL) was used in eleven cases, while eight treatments delivered two doses ( $3 \mathrm{~mL}$ ) each. An average of 1.4 doses $(2.1 \mathrm{~mL})$ of Onyx 34 was used per procedure.

After one embolization procedure, seven patients had successful embolization of their endoleak on follow-up. Three 
Table I Transcatheter embolization of type II endoleaks with Onyx; procedural parameters and outcomes from January 2007 to November 2012

\begin{tabular}{|c|c|c|c|c|c|c|c|c|c|}
\hline Patient & Procedure & $\begin{array}{l}\text { Endograft to } \\
\text { embolization } \\
\text { (months) }\end{array}$ & $\begin{array}{l}\text { Procedure } \\
\text { time (min) }\end{array}$ & $\begin{array}{l}\text { Access } \\
\text { technique } \\
\text { (CT/DF/TA) }\end{array}$ & $\begin{array}{l}\text { Adjunctive } \\
\text { coils placed } \\
(\mathrm{Y} / \mathrm{N})\end{array}$ & $\begin{array}{l}\text { Total } \\
\text { volume of } \\
\text { onyx used }\end{array}$ & $\begin{array}{l}\text { Embolization } \\
\text { follow-up } \\
\text { (months) }\end{array}$ & $\begin{array}{l}\text { Endoleak } \\
\text { on follow-up } \\
(\mathrm{Y} / \mathrm{N})\end{array}$ & $\begin{array}{l}\text { Final change } \\
\text { in aneurysm } \\
\text { sac size }(\mathrm{cm})\end{array}$ \\
\hline A & I & 6.1 & 139 & CT & $Y$ & 1.5 & 6.2 & $N$ & -0.6 \\
\hline B & 2 & 11.3 & 118 & CT & $Y$ & 1.5 & I.I & $\mathrm{N}$ & -0.3 \\
\hline C & 3 & $\mathrm{~N} / \mathrm{A}$ & 103 & CT & $Y$ & 1.5 & 20.1 & $\mathrm{~N}$ & -0.3 \\
\hline D & 4 & 9.9 & 142 & CT & $\mathrm{N}$ & 3 & 64.4 & $N$ & -0.4 \\
\hline $\mathrm{E}$ & 5 & 60 & 94 & DF & $Y$ & 3 & 55.1 & $Y$ & +1.1 \\
\hline $\mathrm{F}$ & 6 & 5.5 & 51 & TA & $Y$ & 3 & 13.2 & $\mathrm{~N}$ & -0.9 \\
\hline \multirow[t]{3}{*}{ G } & 7 & 2 & 237 & TA & $Y$ & 3 & & $Y$ & -0.1 \\
\hline & 8 & & 199 & TA & $Y$ & 1.5 & & $Y$ & +0.2 \\
\hline & 9 & & 79 & DF & $Y$ & 1.5 & 17.1 & $N$ & 0 \\
\hline \multirow[t]{2}{*}{$\mathrm{H}$} & 10 & 6.7 & 103 & DF & $Y$ & 1.5 & & $Y$ & +0.2 \\
\hline & 11 & & 155 & $C T \& D F$ & $\mathrm{~N}$ & 3 & 7.9 & $Y$ & 0 \\
\hline 1 & 12 & 8.2 & 83 & $\mathrm{CT}$ & $Y$ & 1.5 & 13.1 & $Y$ & +0.6 \\
\hline J & 13 & $\mathrm{I}$ & 54 & TA & $\mathrm{N}$ & N/A & 0.5 & $Y$ & 0 \\
\hline K & 14 & 8 & 98 & CT & $Y$ & 1.5 & 7.2 & $\mathrm{~N}$ & -0.2 \\
\hline L & 15 & 8.9 & 197 & TA & $\mathrm{N}$ & 3 & 36.7 & $N$ & -0.3 \\
\hline \multirow[t]{2}{*}{$M$} & 16 & 36 & 137 & TA & $N$ & 3 & & $Y$ & +1.2 \\
\hline & 17 & & 55 & CT & $Y$ & 1.5 & 28 & $N$ & -0.2 \\
\hline \multirow[t]{2}{*}{$\mathrm{N}$} & 18 & 8.9 & 224 & DF & $\mathrm{N}$ & 1.5 & & $Y$ & +0.4 \\
\hline & 19 & & 93 & DF & $\mathrm{N}$ & 1.5 & 8.6 & $\mathrm{~N}$ & 0 \\
\hline
\end{tabular}

Abbreviations: CT, computed tomography guided direct aneurysm sac puncture; DF, direct fluoroscopic puncture of aneurysm sac; TA, transarterial catheter access; Y/N, yes/no.

patients with persistent endoleak after a single endoleak embolization procedure did not have a repeat procedure. A second attempt at endoleak embolization was performed on four patients, resulting in elimination of the endoleak in two patients (though one only evaluated by ultrasound on follow-up), and persistent endoleaks in two patients (though one had a significantly smaller aneurysm sac diameter). One of the two patients with persistent endoleak after two procedure attempts underwent no further treatment. The other patient underwent clinically successful embolization on the third attempt.

Clinically successful endoleak embolization was achieved in 10 of 19 procedures, as evidenced by absence of detectable endoleak on final follow-up evaluation (one was evaluated only by ultrasound). Overall, there was no significant change in aneurysm sac size between pre-embolization and final follow-up imaging. However, of the patients receiving clinically successful endoleak embolization, there was a mean decrease of $0.3 \mathrm{~cm}$ in the aneurysm sac diameter at final follow-up imaging. In contrast, of the patients with persistent endoleak after treatment, there was a mean aneurysm sac diameter increase of $0.4 \mathrm{~cm}$ at final follow-up imaging. Two sample $t$-test analysis demonstrates a statistically significant difference in sac diameter change between these two populations $(p=0.0018)$.

A breakdown of endoleak embolization success based on method of procedural access shows that transarterial access was associated with clinically successful embolization in only two of six (33\%) procedures. CT-guided direct puncture access was associated with successful endoleak embolization in six of eight (75\%) procedures. Fluoroscopic-guided direct puncture access was associated with successful embolization in two of five $(40 \%)$ procedures.

Clinically successful endoleak embolization was also correlated with materials used during the procedure. For cases using Onyx 34 alone, three of seven procedures (42.9\%) were successful. When Onyx 34 and coils were used in conjunction, 7 of 12 procedures $(58.3 \%)$ had no endoleak on final follow-up imaging.

One major complication occurred during the followup period. A patient underwent transarterial embolization 1 month after the initial EVAR procedure. An endograft infection subsequently developed. Successful open surgical explantation with placement of a rifampin-soaked surgical aortic graft was performed. The patient was asymptomatic 8 months later. After this, the protocol was amended to included antibiotic prophylaxis during the procedure.

\section{Discussion}

It is clear that type II endoleaks are associated with increasing aneurysm sac size, and with increased reintervention. ${ }^{5}$ It is recommended to treat type II endoleaks for aneurysm sac expansion $>5 \mathrm{~mm}$ within 6 months, or overall expansion greater than $10 \mathrm{~mm}$ since the intervention. ${ }^{6}$ Our experience 
with a combination of initial and repeat transcatheter embolization procedures using Onyx was that successful resolution of type II endoleak made a statistically significant $(p<0.01)$ difference in aneurysm sac diameter. Despite this, data suggest repeat intervention for type II endoleaks may not reliably decrease likelihood or rate of aneurysm sac expansion. ${ }^{7}$ Therefore, it behooves us treat type II endoleaks as effectively as possible with each intervention.

The main purpose of this submission is to detail our experience with the alternative liquid embolic agent Onyx. This agent has potential technical benefits during transcatheter embolization procedures. Cost-effectiveness compared to other liquid agents is unclear. In addition, general technical considerations for transcatheter type II endoleak embolization need further discussion and investigation.

A few other centers have published their results of offlabel use of Onyx 34 for treatment of endoleaks. In a study of 101 patients with type II endoleaks embolized with Onyx, Massis et $\mathrm{al}^{8}$ successfully achieved resolution of endoleak in $66 \%$ of patients. A study which compared Onyx to other embolic agents suggests that Onyx may be superior as the embolic agent compared to coils or other liquid embolic agents. ${ }^{9}$ At our institution, 10 out of 19 (53\%) of the procedures using Onyx 34, with or without coils, achieved resolution of the endoleak. This is a rate similar to published outcomes from other centers using Onyx, and for published results of other embolic agents.

A recent review paper described a number of the technical advantages of ethylene vinyl copolymer. These included its ability to be deployed against arterial flow and the increased duration of a controlled injection, due to its cohesive properties. ${ }^{4}$ These properties could allow for filling of a relatively large volume of an endoleak flow channel from a remote catheter position prior to occluding the inflow artery (Figure 1). For a needle or catheter position within the flow channel, Onyx has the ability to occlude the flow channel, draining artery, and inflow artery. The viscosity characteristics and cohesive nature of Onyx 34 were likely helpful in preventing any significant inadvertent embolization of Onyx during our procedures.

It was suggested by Larzon and Fujita ${ }^{4}$ that the benefits of Onyx use came at an expensive financial cost. Our center did not share this experience. At the time of data collection, the cost paid by our institution for the average 1.4 doses of Onyx was approximately $67 \%$ the cost of a single use volume of n-butyl cyanoacrylate (NBCA). Aside from choice of liquid embolic agent, other factors are to be considered for treatment efficacy.

\section{Limitations}

There are varied opinions about the impact that access route plays in outcomes of endoleak intervention. Many authors have published that there is a greater rate of successful type II endoleak embolization with direct puncture of the flow channel within the aneurysm sac. ${ }^{3}$ In our study, 9/14 (64\%) of direct puncture approaches achieved resolution, while only $2 / 6(33 \%)$ of transarterial approaches were clinically successful. However, the sample size in our series is too low to reach significance. In addition, the decision to place coils was intimately tied with the choice of access. All CT-guided
A

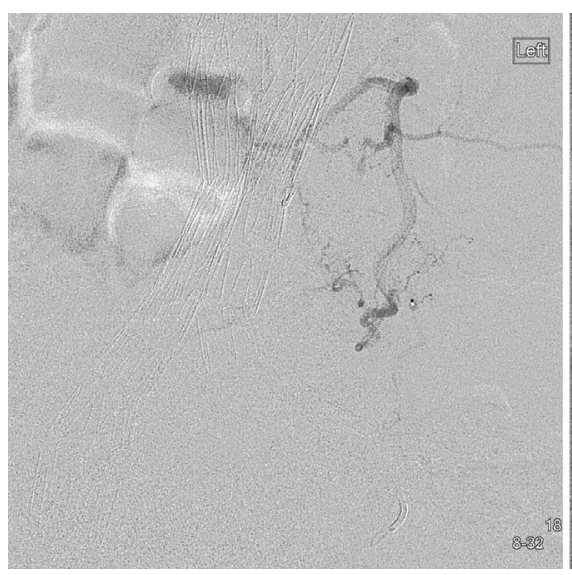

B

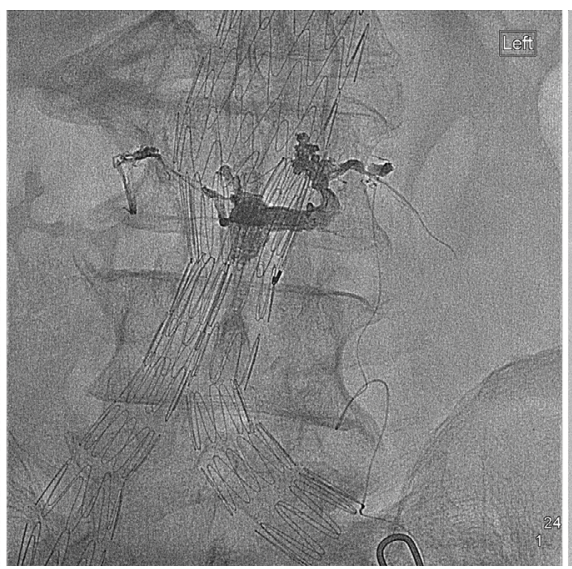

C

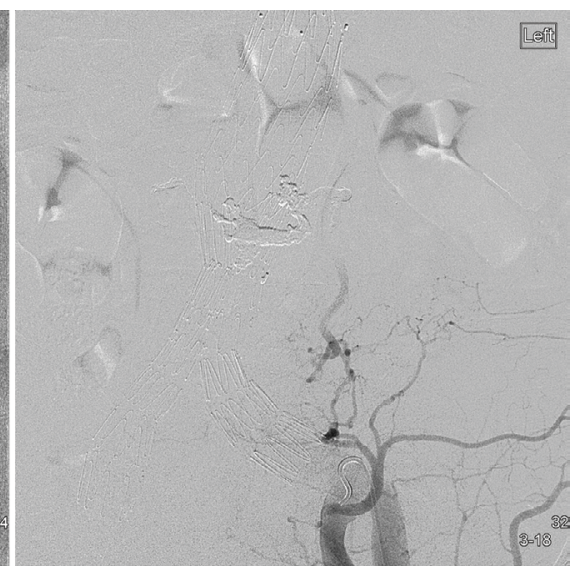

Figure I (A) Digital subtraction angiography after contrast injection within the left iliolumbar artery demonstrating type II endoleak inflow through the left L4 lumbar artery and outflow through a small vessel to the right of the abdominal aortic aneurysm sac. (B) Digital image status postembolization with Onyx demonstrating a high volume deployed downstream into the endoleak flow channel and extruding into the draining vessel. The embolization continues back into the feeding L4 lumbar artery. These emphasize the technical advantage of Onyx's cohesive properties. (C) Digital subtraction angiography demonstrating technical success with lack of flow through the previous feeding vessel. 
direct punctures received coil embolization, a total of eight. A total of 12 embolization procedures used adjunctive coil embolization, with the additional four receiving coils to ensure complete flow channel embolization while using a maximum of two Onyx doses ( $3 \mathrm{~mL})$. This overlap is a confounder limiting evaluation of outcomes related to both access route and synchronous use of coil embolization with Onyx. Further investigation with larger sample sizes would allow for more robust statistical analysis of the impact of each.

Additional notable limitations are present. Small sample size limits statistical analysis. Multiple variables are present from patient to patient, further reducing the study's power. Also, the retrospective approach provides additional potential sources of bias.

\section{Conclusion}

This manuscript contributes to a growing body of mid-term data that suggests use of the liquid cohesive embolic agent Onyx is both safe and effective for treatment of type II endoleaks. Furthermore, statistically significant decreased aneurysm sac size was associated with clinically successful endoleak embolization procedures $(p<0.01)$. Onyx offers potential technical, and in some regions, cost benefits over NBCA and should be further investigated. However, the best technical method is not clearly defined. Our data suggests improved results with CT-guided direct puncture techniques and with synchronous use of embolic coils. But the sample sizes are much too small for statistical evaluation of these. Therefore, further larger scale investigation into use of Onyx with differing technical parameters is warranted to help make treatment planning decisions.

\section{Acknowledgment}

An original research manuscript based on data originally presented at the Radiological Society of North America
(RSNA) meeting in 2012. Presented at the RSNA. Based on the University of Vermont Institutional Review Board, Committee on Human Research in the Medical Sciences exemption titled "Transcatheter Embolization of Abdominal Aortic Endograft Endoleaks Using Onyx and Colls: Experience at a Regional Tertiary Care Referral Center". The exemption was granted based on the data being "...recorded by the investigator in such a manner that subjects cannot be identified, directly or through identifiers linked to the subjects."

\section{Disclosure}

The authors report no conflicts of interest in this work.

\section{References}

1. Ozdemir BA, Chung R, Benson RA, et al. Embolisation of type 2 endoleaks after endovascular aneurysm repair. $J$ Cardiovasc Surg (Torino). 2013;54(4):6.

2. Green N, Sidloff DA, Stather PW, Bown MJ, Sayers RD, Choke E Endoleak after endovascular aneurysm repair: current status. Rev Vasc Med. 2014;2(2):43-47.

3. Sidloff DA, Stather PW, Choke E, Bown MJ, Sayers RD. Type II endoleak after endovascular aneurysm repair. Br J Surg. 2013;100(10):1262-1270.

4. Larzon T, Fujita S. Type II endoleak: a problem to be solved. J Cardiovasc Surg. 2014;55(1):109-118.

5. Cieri E, De Rango P, Isernia G, et al. Type II endoleak is an enigmatic and unpredictable marker of worse outcome after endovascular aneurysm repair. J Vasc Surg. 2014;59(4):930-937.

6. Patatas K, Ling L, Dunning J, Shrivastava V. Static sac size with a type II endoleak post-endovascular abdominal aortic aneurysm repair: surveillance or embolization? Interact Cardiovasc Thorac Surg. 2012;15(3):462-466.

7. van Marrewijk CJ, Fransen G, Laheij RJ, Harris PL, Buth J, Collaborators E. Is a type II endoleak after EVAR a harbinger of risk? Causes and outcome of open conversion and aneurysm rupture during follow-up. Eur J Vasc Endovasc Surg. 2004;27(2):128-137.

8. Massis K, Carson WG 3rd, Rozas A, Patel V, Zwiebel B. Treatment of type II endoleaks with ethylene-vinyl-alcohol copolymer (Onyx). Vasc Endovascular Surg. 2012;46(3):251-257.

9. Abularrage CJ, Patel VI, Conrad MF, Schneider EB, Cambria RP, Kwolek CJ. Improved results using Onyx glue for the treatment of persistent type 2 endoleak after endovascular aneurysm repair. J Vasc Surg. 2012;56(3):630-636.
Journal of Vascular Diagnostics and Interventions

\section{Publish your work in this journal}

The Journal of Vascular Diagnostics and Interventions is an international, peer-reviewed journal of diagnostics, focusing on non invasive vascular investigation methods involved in the evaluation of vascular diseases. The journal is committed to the rapid publication in the fields of vascular diseases. Original research, review, case reports, expert

\section{Dovepress}

opinion and commentaries are all considered for publication. The manuscript management system is completely online and includes a very quick and fair peer-review system, which is all easy to use. Visit $\mathrm{http}: / / \mathrm{www}$. dovepress.com/testimonials.php to read real quotes from published authors. 